\title{
Akut gastrik dilatasyon
}

\author{
Acute gastric dilatation
}

Yirmialtı yaşında kadın hasta, 10 gündür olan her iki ayak sırtında ve topuklarında şişlik şikayetiyle polikliniğimize müracaat etti. Özgeçmişinde 9 aylıkken geçirilmiş febril konvulziyone sekonder gelişme geriliği, mental retardasyon, afazi, kuadriparezi ve 16 yaşından itibaren epilepsi öyküsü vardı. Yakınlarından alınan sistem sorgusunda oral alım azlığı, 4-5 gündür olan kuru öksürük şikayeti vardı. Hastanın kabul muayenesinde yaygın diş kaybı, diş eti hipertrofisi, torakal ve lomber skolyoz, 3+ pretibial ödem mevcuttu. Direkt grafide (Resim 1) $25 \mathrm{~cm} \times 15 \mathrm{~cm}$ çaplı içerisinde seviyelenme olmayan mide havası olarak yorumladığımız alan mevcuttu. Oniki saat oral beslenmenin kesilmesi sonrası çekilen kontrol batın grafisinde (Resim 2) gastrik dilatasyona ve hava sıvı seviyesine rastlanılmadı. Batın muayenesi doğal olan ve gaz gaita çıkışı normal olan hastada gastrik dilatasyonun spontan gerilediği görüldü.

Akut gastrik dilatasyon ilk olarak 1833 yııında Duplay tarafından tanımlanmıştır. Vakaların çoğunluğu postoperatif dönemde gözlenir. Akut gastrik dilatasyon etyolojisinde intestinal obstrüksiyon, herniasyon, travma, elektrolit bozukluğu ve anoreksiya nevrozanın yer aldığı ciddi mortalite ve morbidite ile seyreden nadir görülen bir durumdur. Literatüre baktığımızda bir çok vakanın postoperatif dönemde görüldüğü, gastrik nekroz ve perforasyon ile seyrettiği ve cerrahi

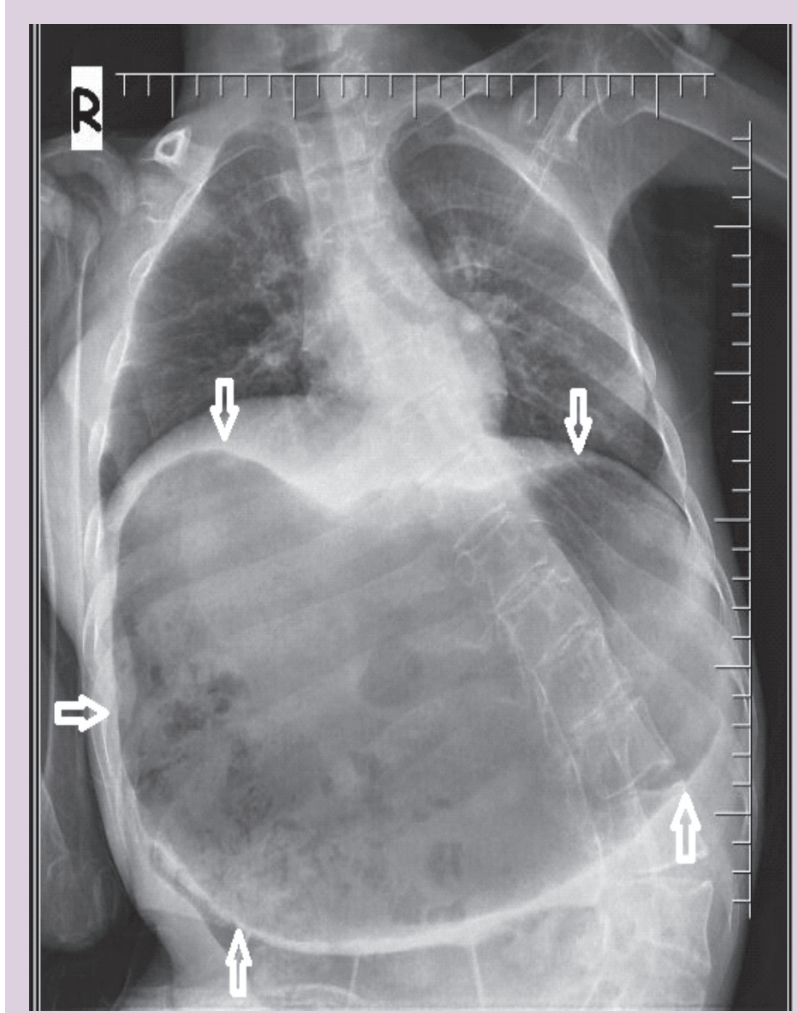

Resim 1: Direkt grafide $25 \mathrm{~cm}$ x $15 \mathrm{~cm}$ çaplı içerisinde seviyelenme olmayan mide havası görülmektedir. (Beyaz oklar).

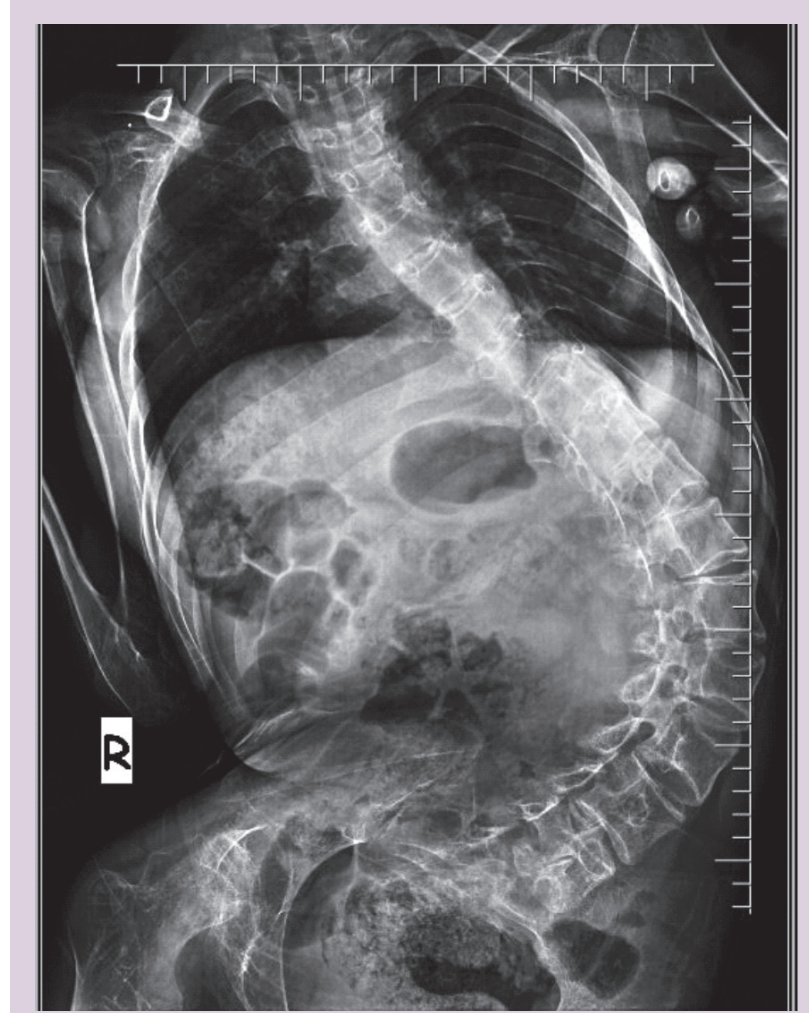

Resim 2: Oniki saat oral beslenmenin kesilmesi sonrası çekilen kontrol batın grafisinde gastrik dilatasyonun gerilediği görüldü, hava sıvı seviyesine rastlanılmadı. Gastrik dilatasyonu gerilemesi sonrası skolyoz daha belirgin olarak görülmektedir. 
ERMiș ve ark.

tedavi gerektiğini gördük. Birkaç olgu sunumunda serebral palsi ve skolyoz ile birliktelik göstermektedir (1-3). Bizim vakamızda asemptomatik mide dilatasyonu ve spontan regresyonu gözlemledik. Mide dilatasyonun serebral palsi, skolyoz ve kuadripareziyle birliktelik gösteren ve spontan regrese olan, nadir görülen bu olguyu klinik imaj olarak sunduk.

Fatih ERMiş', Alper KOÇ², Ramazan BÜYÜKKAYA ${ }^{3}$, Ali KUTLUCAN², Yusuf AYDIN²

Düzce Üniversitesi Tıp Fakültesi, ' Gastroenteroloji Bilim Dalı, ${ }^{2}$ lç Hastalıkları Anabilim dalı, ${ }^{3}$ Radyoloji Anabilim Dalı, Düzce

\section{YORUM}

Akut gastrik dilatasyon çok nadir görülen, fatal olabilen bir patolojidir. Etyopatogenezi tam açıklanamamıştır. Mekanik obstrüksiyon sonucu gelişebilirken, tıkayııı patoloji olmayan olgular da vardır. Sunulan olgu sadece oral alımın kesilmesi ile kendiliğinden düzelmiş olmakla birlikte böyle olgularda aşııı dilate mide'nin vasküler sisteme basısına bağlı iskemik olaylar, kompartman sendromu veya mide duvarında infarktüs, nekroz ve perforasyon gelişebilir. Bundan dolayı olgulara genellikle daha dinamik bir yaklaşım ile nazogastrik tüp veya gastroskopik dekompresyon uygulanmıştır. Ayrıca sunulan bu olguya, takiben mide çıkış bölgesini değerlendirmek için uygun görüntüleme yöntemlerinin uygulanması faydalı olurdu.

Prof. Dr. Orhan SEZGiN

Özgün Görüntüler Editörü

\section{KAYNAKLAR}

1- Abdu RA, Garritano D, Culver O. Acute gastric necrosis in anorexia nervosa and bulimia. Two case reports. Arch Surg. 1987; 122(7): 830-2.

2- Todd SR, Marshall GT, Tyroch AH. Acute gastric dilatation revisited. Am Surg. 2000;66: 709-710.
3- Byard RW, Couper RT. Acute gastric dilation and spastic quadriparesis. J Pediatr. 2001; 139:166. 